\title{
Peripheral Blood Eosinophils and Nine Years Mortality in COPD Patients
}

This article was published in the following Dove Press journal:

International Journal of Chronic Obstructive Pulmonary Disease

\section{Robson Prudente (i) \\ Renata Ferrari $\mathbb{D}$ \\ Carolina B Mesquita $\mathbb{D}$ \\ Luiz HS Machado \\ Estefânia AT Franco \\ Irma Godoy \\ Suzana E Tanni (D)}

Department of Internal Medicine, Botucatu School of Medicine, São Paulo State University (UNESP), Botucatu, São Paulo, Brazil
Correspondence: Robson Prudente Department of Internal Medicine, Botucatu Medical School, São Paulo State University (UNESP), Av. Prof.

Montenegro, s/n, Distrito de Rubião Junior, Botucatu, São Paulo, 18618-970, Brazil

Tel +55 I4 99734-9653

Email robsonapp@gmail.com
Background: Eosinophil counts increase during chronic obstructive pulmonary disease (COPD) exacerbation and influence the response to different agents (such as inhaled and systemic corticosteroids), as well as increase the production of other inflammatory cytokines. However, few studies have evaluated the association between peripheral blood eosinophils with mortality rate.

Objective: To evaluate the association between peripheral blood eosinophils and mortality rate in COPD patients over a nine-year period.

Study Design and Methods: This cohort included 133 COPD patients assessed at baseline by spirometry, pulse oximetry $\left(\mathrm{SpO}_{2}\right)$, complete blood count, body composition, dyspnea intensity [Modified Medical Research Council (mMRC)] and the six-minute distance test (6MWD). The Kaplan-Meier curve followed by a Log rank test was used to evaluate mortality rate related to eosinophil cutoff point categorization. Multivariate Cox regression analysis was performed to identify the association between eosinophils and mortality with all subjects evaluated at baseline, adjusted for age, gender, mMRC, 6MWT, forced expiratory volume in the first second $\left(\mathrm{FEV}_{1}\right)$ and $\mathrm{SpO}_{2}$.

Results: Nineteen patients did not complete follow-up and it was not possible to identify the date of death in four others. Therefore, 110 patients were included in the analysis. At baseline, $81 \%$ presented $\geq 150$ eosinophil cells and $72 \%$ presented $\geq 2 \%$. We identified a three-fold higher risk of death in those with $<2 \%$ eosinophils and $<150$ cells. We did not identify statistical differences when using other cutoff points.

Conclusion: The decrease in number of peripheral eosinophils, with cutoff points at $2 \%$ and 150 cells, may be associated with a higher risk of death in COPD patients over nine years.

Keywords: chronic airflow obstruction, inflammation, death rate

\section{Background}

Chronic obstructive pulmonary disease (COPD) is characterized by persistent airflow limitation and lung function decline. The pathological changes in COPD include chronic inflammation with increases in specific types of inflammatory cells. ${ }^{1}$ Eosinophils previously considered anti-inflammatory cells involved in protection against parasitic infections and allergic disease responses ${ }^{2,3}$ are also being investigated as inflammatory cells in COPD. ${ }^{4}$ Under specific conditions, eosinophils can be recruited to tissues and chemokines, and cytokines and cytotoxic granular products derived from eosinophils may facilitate an inflammatory reaction. $^{2,4}$

Neutrophilic inflammation is a typical finding, however, the role of eosinophils in COPD is not yet fully understood. Studies have shown that both neutrophil and 
eosinophil counts increase during COPD exacerbations. ${ }^{5,6}$ Eosinophils influence the response to different agents (such as inhaled and systemic corticosteroids) and can increase the production of other inflammatory cytokines such as Interleukin 6 and Tumor necrosis factor alpha. ${ }^{2,4}$ The prevalence of higher eosinophils values in COPD patients depends on the eosinophil threshold; ${ }^{7}$ but up to $40 \%$ of these patients have eosinophilic airway inflammation, ${ }^{8}$ a third have sputum eosinophilia, ${ }^{9,10}$ and up to $60 \%$ have higher blood eosinophil levels. ${ }^{11}$

Recent studies have shown an association between eosinophil count and the risk of disease exacerbation and response to inhaled corticosteroid (ICS). ${ }^{12,13}$ On the other hand, there is little research evaluating the prognostic risk of eosinophils on mortality rate and data are inconsistent.

In this context, longitudinal studies related to the association between eosinophils and mortality in COPD patients are still scarce and controversial. Thus, our hypothesis in this study is that lower eosinophil counts have a prognostic association with mortality. Therefore, the aim of this study is to evaluate the association between peripheral eosinophils and mortality rate in COPD patients over a nine-year period.

\section{Patients and Methods}

This investigation was part of the study entitled "Predictors of mortality in patients with COPD after 9 years", approved by Botucatu School of Medicine Research Ethics Committee (approval number: 1.527.377) and was conducted in accordance with the principles of the Declaration of Helsinki. The applied methodology was the same used in this previous study, where further details can be found. ${ }^{14}$

In general, between July 2004 and August 2006, the patients followed up at the University Hospital outpatient clinic at Botucatu School of Medicine were invited to participate in the study. During the medical appointment, the objectives and methods of the research were clarified, thus after signing the informed consent form, 133 COPD patients were recruited. Inclusion criteria were patients diagnosed with COPD, clinical stability three months before assessment and optimized drug therapy, including ICS. Exclusion criteria were patients with diagnoses of other respiratory diseases, noncompliance with treatment, and myocardial infarction four months before assessment.

The patients were assessed at baseline by blood count, smoking history and cessation, quality of life, sensation of dyspnea, pulse oximetry, pulmonary function, nutritional status, exercise tolerance and presence of comorbidities. These patients were followed for nine years by medical appointments and telephone contact at least every six months. Telephone contact was also carried out to obtain the authorization from family members-by signing the informed consent form -, to confirm the patient's clinical condition and when necessary, the cause of death was obtained from family members. A telephone contact was also performed to use data from patients who died during the follow-up. In addition, all notes from the medical records were used for confirmation of the cause of death. The number of exacerbations was only considered in the first three years of follow-up, as it was only possible to count exacerbations with greater accuracy over this period.

\section{Statistical Analysis}

Absolute Eosinophil and percentage of total peripheral leukocytes cutoff points were determined by sample distribution third quartile (75\% percentile) and the Receiver Operating Characteristic (ROC) curve in relation to state of life after nine years follow-up. These cutoff points were used to assess associations with mortality over nine years.

The Kaplan-Meier curve followed by the Log rank test were used to evaluate mortality rate related to categorization of eosinophil cutoff points. These were categorized as follows: $<150$ or $\geq 150$ and $<2 \%$ or $\geq 2 \%$. ${ }^{4}$ Multivariate Cox regression analysis was performed to identify the association between eosinophils and mortality including all subjects evaluated at baseline, adjusting for clinical variables (age, gender, mMRC, 6MWT, FEV 1 and $\left.\mathrm{SpO}_{2}\right){ }^{15}$

The significance level was set at $\mathrm{P}<0.05$. All data were analyzed using SPSS version 17.0 (SPSS - IBM Software, Dallas, TX, USA).

\section{Results}

Of the total patients initially evaluated, nineteen stopped follow-up and four did not have their cause of death identified; therefore, 110 patients [67\% male, $65 \pm 9$ years old, and $\left.\mathrm{FEV}_{1}: 52.5(40-73 \%)\right]$ were included in the mortality analysis.

Sixty-four patients died during follow-up; causes of deaths were: 41 respiratory failure, 9 neoplasm (lung and others), 5 cardiovascular disease, and 5 other causes. Four patients were excluded from the analyses due to a lack of information concerning date and cause of death. The relationship between cause of death and 2004 GOLD severity classification at baseline is shown in Figure 1. 


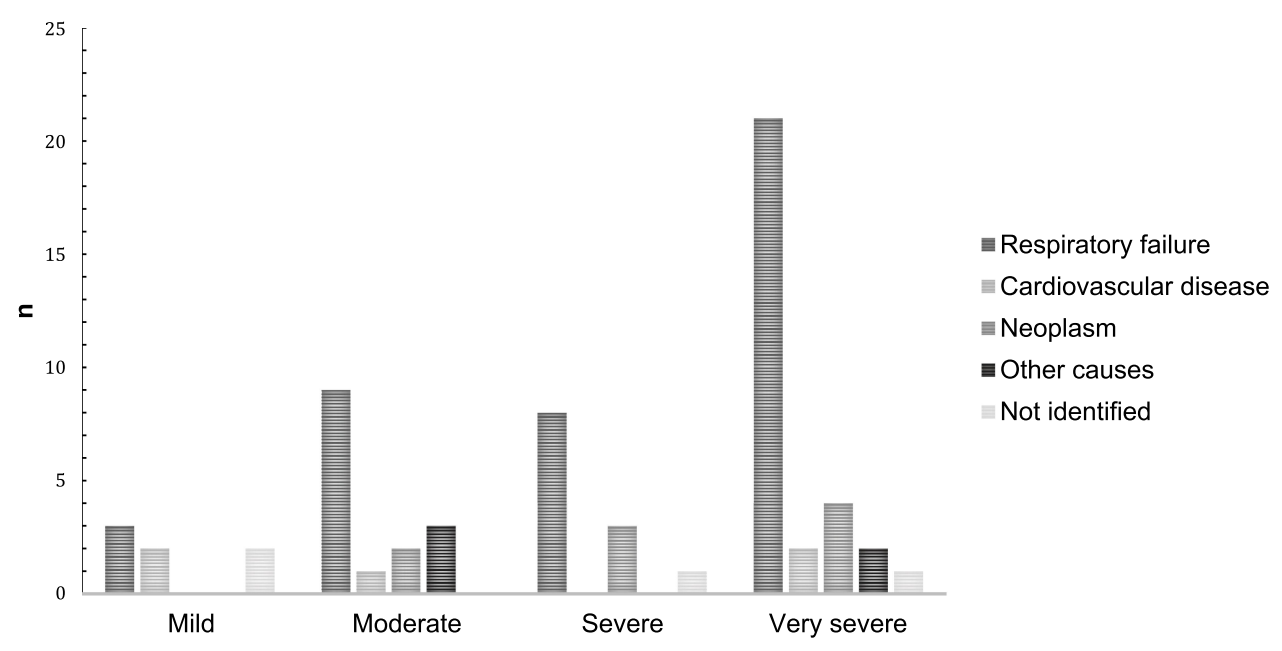

Figure I Cause of death according to 2004 GOLD severity classification at baseline.

The demographic and clinical characteristics of the patients involved in the survival analysis have been also included in a previous publication. ${ }^{14}$ In summary, 72 patients were active smokers at baseline with no difference between the groups according to COPD severity. There were a higher proportion of men in the severe to very severe group compared to the mild to moderate COPD group. There were no differences in BMI between severity groups and 19\% of patients with mild to moderate COPD and $23 \%$ of patients with severe to very severe COPD presented BMI $<21 \mathrm{~kg} / \mathrm{m}^{2}$. We found a higher prevalence of body mass depletion and $38 \%$ in both groups had fat-free mass depletion. Besides that, according to the 2004 GOLD classification, most patients were not using bronchodilators and 15 patients with moderate COPD, five with severe COPD and 13 with very severe COPD used ICS.

Regarding eosinophil distribution in peripheral blood at baseline $[270(195-550)$ cells], we identified that 10 patients presented values higher than 1000 eosinophils.
When we evaluated the percentage of eosinophils in relation to total leukocytes [3.9 (2.7-6.5) \%], we identified 11 patients with values higher or equal to $10 \%$ (Figure 2).

In categorizing eosinophils by the Kaplan-Meier curve followed by the Log Rank test, we can only see an association between mortality and the $\geq 2 \%$ cutoff point from scientific literature $(p=0.03)$. The $\geq 150$ cell cutoff point did not present statistical difference (Figure 3).

In the Cox regression analysis adjusted for the following variables: male gender, age (years), $\mathrm{SpO}_{2}(\%), \mathrm{FEV}_{1}$, 6MWT and mMRC; when considering the $<2 \%$ and $<150$ cell cutoff points, we identified a three-fold higher risk of death in those with $<2 \%$ eosinophils \{Hazard Ratio [HR]: 3.13 [95\% confidence interval $(95 \% \mathrm{CI}): 1.38-7.07]$; $\mathrm{p}=0.006\}$ (Table 1) and $<150$ cells [HR: $3.02(95 \% \mathrm{CI}$ : 1.42-6.42); $\mathrm{p}=0.004$ ] (Table 2) in nine years.

According to the cutoff points analyzed, there was no effect of number of eosinophils on exacerbation rate.

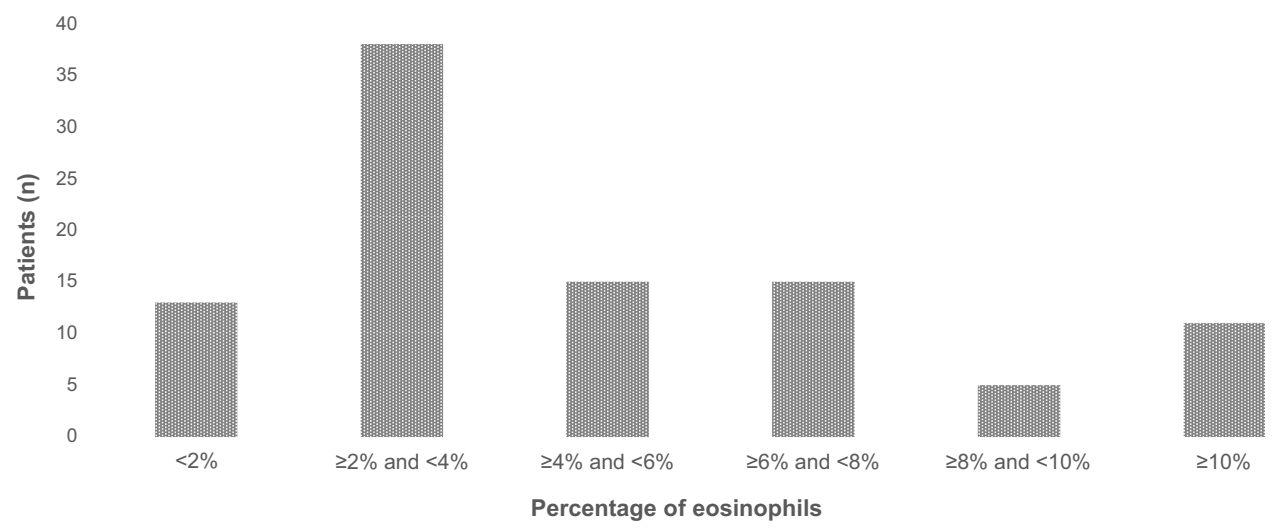

Figure 2 Percentage of eosinophils in relation to total leukocytes. 

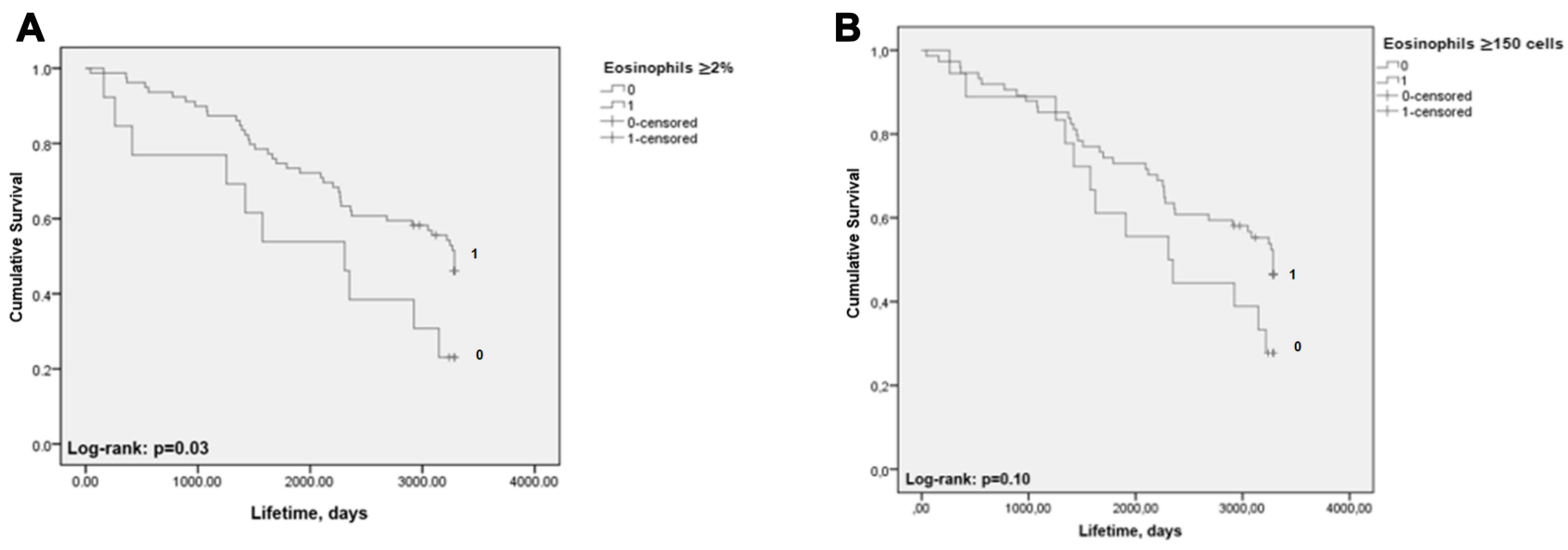

Figure 3 Kaplan-Meier curve in relation to categorizing patients with eosinophils $\geq 2 \%$ (A) and $\geq 150$ cells (B).

\section{Discussion}

The main aim of this study was to evaluate the association between peripheral eosinophils and mortality rate in COPD patients over nine years. Our results suggest that

Table I Cox Regression Analysis to Evaluate the Association Between Percentage of Eosinophils $<2 \%$ and Mortality Over Nine Years

\begin{tabular}{|l|c|c|}
\hline Variables & Hazard Ratio (IC95\%) & p value \\
\hline Gender (male) & $0.62(0.78-3.38)$ & 0.20 \\
Age (years) & $1.02(0.98-1.07)$ & 0.35 \\
$\mathrm{SpO}_{2}(\%)$ & $0.92(0.84-1.00)$ & 0.06 \\
$\mathrm{FEV}_{1}, \%$ & $1.00(0.99-1.02)$ & 0.72 \\
6MWT, meters & $0.99(0.99-0.99)$ & 0.01 \\
mMRC, score & $1.07(0.75-1.53)$ & 0.70 \\
\hline Eosinophil: $\geq 2 \%$ (ref) & & \\
$<2 \%$ & $3.13(1.38-7.07)$ & 0.006 \\
\hline
\end{tabular}

Abbreviations: $\mathrm{SpO}_{2}$, pulse oximetry; $\mathrm{FEV}_{1}$, forced expiratory volume in the first second; mMRC, Medical Research Council modified; 6MWT, distance walked in the six-minute walk test.

Table 2 Cox Regression Analysis to Evaluate the Association Between $<150$ Eosinophil Cells and Mortality Over Nine Years

\begin{tabular}{|l|c|c|}
\hline Variables & Hazard Ratio (IC95\%) & p value \\
\hline Gender (male) & $1.86(0.83-4.17)$ & 0.13 \\
Age (years) & $1.03(1.00-1.10)$ & 0.03 \\
$\mathrm{SpO}_{2}(\%)$ & $0.90(0.83-0.98)$ & 0.01 \\
$\mathrm{FEV}_{1}, \%$ & $1.00(0.99-1.02)$ & 0.80 \\
6MWT, meters & $0.99(0.99-1.00)$ & 0.10 \\
mMRC, score & $1.09(0.73-1.61)$ & 0.68 \\
\hline Eosinophil: $\geq 150$ cells (ref) & & \\
<150 & $3.02(1.42-6.42)$ & 0.004 \\
\hline
\end{tabular}

Abbreviations: $\mathrm{SpO}_{2}$, pulse oximetry; $\mathrm{FEV}_{1}$, forced expiratory volume in the first second; mMRC, Medical Research Council modified; 6MWT, distance walked in the six-minute walk test. low eosinophil values ( $<2 \%$ and $<150$ cells) were good biomarkers for predicting COPD mortality.

Few studies have investigated eosinophil prognostic value in COPD patients. ${ }^{16-19}$ Consistent with our results, Rahimi-Rad et $\mathrm{al}^{18}$ conducted a study with 100 patients and reported a significant relationship between eosinopenia and outcomes in patients with acute COPD exacerbation, such as longer hospital stay, increased need for mechanical ventilation and higher in-hospital mortality. Mendy et $\mathrm{al}^{19}$ followed 431 patients with COPD for a median time of 36 months and verified that low eosinophil count $(<2 \%)$ was associated with increased risk of mortality.

On the other hand, several studies did not show an association between eosinophil count and the risk of exacerbation or mortality. ${ }^{4,20-22}$ Ho et $\mathrm{al}^{20}$ showed that although a higher eosinophil count was associated with reduced length of hospital stay, there was no difference in the risk of exacerbation in 12 months and in-hospital mortality in groups of patients with eosinophilic and noneosinophilic COPD. This was also demonstrated in a recent study by Adir et $\mathrm{al}^{22}$ who aimed to investigate the influence of eosinophils on exacerbation in 992 COPD patients over 10 years. The authors found that although the majority of patients presented eosinophil values greater than $2 \%$, there were no significant associations with the risk of severe exacerbation or response to ICS.

Low et $\mathrm{al}^{23}$ evaluated 646 COPD patients with alphaantitrypsin deficiency and eosinophilia defined as $>0.2 \times 109 / \mathrm{L}$, classifying the frequency of such counts into "always," "intermittent" or "never present." Mortality rate did not differ according to eosinophilic group. Similarly, another study ${ }^{24}$ did not show any 
association between mortality over one year with eosinophil counts in patients who had presented previous exacerbation. In contrast, some studies have shown that it is not eosinophilia, but the presence of eosinopenia that could be associated with higher risk of death. ${ }^{16,17} \mathrm{~A}$ study conducted by Holland et $\mathrm{al}^{16}$ showed that in 65 hospitalized COPD patients, those with eosinopenia $(<40$ peripheral cells) had a higher risk of mortality than those with normal eosinophils. Another study with 920 COPD exacerbation patients showed that in the predictive model of mortality during hospitalization, the presence of eosinophil values below $0.05 \times 109 / \mathrm{L}$ was mortality predictive. ${ }^{17}$

We would like to emphasize that our findings showed a lower proportion of patients with eosinopenia (19\% with $<150$ cells $/ \mu \mathrm{L}$ and $28 \%$ with $<2 \%$ ), as observed by Rahimi-Rad et al $^{18}$ and Mendy et al, ${ }^{19}$ however, at this time, it was not possible to associate the worst outcomes with the lowest proportion of patients, considering that Adir et $\mathrm{al}^{22}$ also found a lower proportion of patients with eosinopenia (28\%) but without associations to risk of exacerbation or mortality.

In addition to the $2 \%$ cutoff point, our findings showed that patients with absolute eosinophil numbers $<150$ cells/ $\mu \mathrm{L}$ also have a three-fold increased risk of death. In the study by Rahimi-Rad et al $^{18}$ cited above, the absolute number of cells of patients who died was on average 44.0 cells, whereas that of survivors was 107.4 cells $(\mathrm{p}=0.022)$. Even though both were below our cutoff point, patients who died still had lower absolute numbers of blood eosinophils. The number of eosinophils in blood may be influenced by other factors such as allergic and infectious disorders in addition to the use of drugs or nutritional supplements which may also influence increases or decreases in their numbers. Therefore, when considering blood eosinophil count, the clinician should pay attention to all these factors. ${ }^{25-28}$

Approximately $65 \%$ of the patients who died during follow-up presented the most severe forms of COPD with lower eosinophil values. In this sense, when analyzing the number of eosinophils in patients with COPD, it was observed that even with cell counts inversely correlating with $\mathrm{FEV}_{1}$, patients classified as GOLD IV did not present sputum eosinophils, suggesting that at some point in the natural history of the disease the inflammatory process becomes mild and its markers become less evident than with $\mathrm{FEV}_{1} \cdot{ }^{6,29}$ However, it should also be considered that inflammation can reduce due to the degranulation process that eosinophilic cells undergo in COPD. Degranulation may be due to the neutrophil elastase commonly increased in the disease and, consequently, are not visualized by the microscope, which further favors the reduction of cell counts according to the course of COPD. ${ }^{30,31}$

A previous study with the same population showed that patients with high BODE index (stands for Body mass index, airflow Obstruction, Dyspnea and Exercise capacity), that is, with the most severe form of the disease, also presented a higher risk of death in nine years and, in this situation, it raises the dilemma of whether COPD severity was influenced by the low eosinophil values or the lower cell count occurred because of COPD severity. ${ }^{14}$ In addition, it was observed that those with a higher frequency of exacerbations in the first 3 years also presented a higher risk of death, which collaborate the relationship between eosinophil reduction, exacerbation and mortality in COPD. However, more specific correlations are needed for a clearer understanding. ${ }^{6,14,32}$

Lastly, our study has limitations that merit comment. A critical point discussed by several authors is that a single measurement of blood eosinophils may not indicate a stable condition, as a considerable proportion of patients may exhibit fluctuating eosinophil levels over the years. ${ }^{43-35}$ We can therefore consider that the analysis of repeated measurements over time could better explain the influence of eosinophils on COPD patient mortality, suggesting the need for further studies on the subject. In addition, other limitations include loss of follow-up of $\sim 17 \%$, the failure to identify all the causes of death of the patients and subject's ability to recall and report past exposures (recall bias).

In conclusion, further longitudinal studies are needed to confirm the findings of this study. We highlight that we did not aim to identify cause and effect, which means that we can only affirm possible associations between the decrease in the number of peripheral eosinophils with cutoff points at $2 \%$ and 150 cells with a higher risk of death in COPD patients over nine years.

\section{Author Contributions}

All authors made a significant contribution to the work reported, whether that is in the conception, study design, execution, acquisition of data, analysis and interpretation, or in all these areas; took part in drafting, revising or critically reviewing the article; gave final approval of the version to be published; have agreed on the journal to which the article has been submitted; and agree to be accountable for all aspects of the work. 


\section{Disclosure}

The authors declare that they have no conflicts of interest for this work.

The abstract of this paper has been presented at the ERS International Congress 2018 as a poster presentation. The poster's abstract was published in the European Respiratory Journal 2018 52: OA5383; DOI: 10.1183/ 13993003.congress-2018.OA5383: [https://erj.ersjournals. com/content/52/suppl_62/OA5383].

\section{References}

1. Persson LJ, Aanerud M, Hiemstra PS, Hardie JA, Bakke PS, Eagan TML. Chronic obstructive pulmonary disease is associated with low levels of vitamin D. PLoS One. 2012;7(6):e38934. doi:10.1371/journal.pone.0038934

2. Kita H. Eosinophils: multifunctional and distinctive properties. Int Arch Allergy Immunol. 2013;161(s2):3-9. doi:10.1159/000350662

3. Furuta GT, Atkins FD, Lee NA, Lee JJ. Changing roles of eosinophils in health and disease. Ann Allergy Asthma Immunol. 2014;113 (1):3-8. doi:10.1016/j.anai.2014.04.002

4. Bafadhel M, Pavord ID, Russell REK. Eosinophils in COPD: just another biomarker? Lancet Respir Med. 2017;5(9):747-759. doi:10.1016/S2213-2600(17)30217-5

5. Saetta M, Di stefano AN, Maestrelli P, et al. Airway eosinophilia in chronic bronchitis during exacerbations. Am J Respir Crit Care Med. 1995;152(6 Pt 1):1926-1931. doi:10.1164/ajrccm.152.6.8520757

6. Queiroz CF, Lemos ACM, Bastos MLS, et al. Inflammatory and immunological profiles in patients with COPD: relationship with FEV 1 reversibility. $J$ Bras Pneumol. 2016;42(4):241-247. doi:10.1590/s1806-37562015000000122

7. Tashkin DP, Wechsler ME. Role of eosinophils in airway inflammation of chronic obstructive pulmonary disease. Int J Chron Obstruct Pulmon Dis. 2018;13:335-349. doi:10.2147/COPD.S152291

8. Saha S, Brightling CE. Eosinophilic airway inflammation in COPD. Int J Chron Obstruct Pulmon Dis. 2006;1(1):39-47. doi:10.2147/ copd.2006.1.1.39

9. Eltboli O, Bafadhel M, Hollins F, et al. COPD exacerbation severity and frequency is associated with impaired macrophage efferocytosis of eosinophils. BMC Pulm Med. 2014;14(1):112. doi:10.1186/14712466-14-112

10. Pizzichini E, Pizzichini MM, Gibson P, et al. Sputum eosinophilia predicts benefit from prednisone in smokers with chronic obstructive bronchitis. Am J Respir Crit Care Med. 1998;158(5):1511-1517. doi:10.1164/ajrccm.158.5.9804028

11. Pavord ID, Lettis S, Anzueto A, Barnes N. Blood eosinophil count and pneumonia risk in patients with chronic obstructive pulmonary disease: a patient-level meta-analysis. Lancet Respir Med. 2016;4(9):731-741. doi:10.1016/S2213-2600(16)301 48-5

12. Pascoe S, Locantore N, Dransfield MT, Barnes NC, Pavord ID. Blood eosinophil counts, exacerbations, and response to the addition of inhaled fluticasone furoate to vilanterol in patients with chronic obstructive pulmonary disease: a secondary analysis of data from two parallel randomised controlled trials. Lancet Respir Med. 2015;3(6):435-442. doi:10.1016/S2213-2600(15)001 $06-\mathrm{X}$

13. Watz H, Tetzlaff K, Wouters EF, et al. Blood eosinophil count and exacerbations in severe chronic obstructive pulmonary disease after withdrawal of inhaled corticosteroids: a post-hoc analysis of the WISDOM trial. Lancet Respir Med. 2016;4(5):390-398. doi:10. 1016/S2213-2600(16)00100-4
14. Prudente R, Franco EAT, Mesquita CB, Ferrari R, de Godoy I, Tanni SE. Predictors of mortality in patients with COPD after 9 years. Int J Chron Obstruct Pulmon Dis. 2018;13:3389-3398. doi:10.2147/COPD.S174665

15. Hulley SB, Cummings SR, Browner WS, Grady DG, Newman TB. Delineando a Pesquisa Clínica. Porto Alegre: Artmed; 2015.

16. Holland M, Alkhalil M, Chandromouli S, Janjua A, Babores M. Eosinopenia as a marker of mortality and length of stay in patients admitted with exacerbations of chronic obstructive pulmonary disease. Respirology. 2010;15(1):165-167. doi:10.1111/j.14401843.2009.01651.x

17. Steer J, Gibson J, Bourke SC. The DECAF score: predicting hospital mortality in exacerbations of chronic obstructive pulmonary disease. Thorax. 2012;67(11):970-976. doi:10.1136/thoraxjnl-2012-202103

18. Rahimi-Rad MH, Asgari B, Hosseinzadeh N, Eishi A. Eosinopenia as a marker of outcome in acute exacerbations of chronic obstructive pulmonary disease. Maedica (Buchar). 2015;10:10-13.

19. Mendy A, Forno E, Niyonsenga T, Gasana J. Blood biomarkers as predictors of long-term mortality in COPD. Clin Respir J. 2018;12 (5):1891-1899. doi:10.1111/crj.12752

20. Ho J, He W, Chan MTV, et al. Eosinophilia and clinical outcome of chronic obstructive pulmonary disease: a meta-analysis. Sci Rep. 2017;7(1):13451. doi:10.1038/s41598-017-13745-x

21. Zysman M, Deslee G, Caillaud D, et al. Relationship between blood eosinophils, clinical characteristics, and mortality in patients with COPD. Int J Chron Obstruct Pulmon Dis. 2017;12:1819-1824. doi:10.2147/COPD.S129787

22. Adir Y, Hakrush O, Shteinberg M, Schneer S, Agusti A. Circulating eosinophil levels do not predict severe exacerbations in COPD: a retrospective study. ERJ Open Res. 2018;4(3):00022-2018. doi:10.1183/23120541.00022-2018

23. Low EV, Hughes SM, Zaffarullah S, Kantas D, Stockley RA, Turner AM. ICS use may modify $\mathrm{FEV}_{1}$ decline in $\alpha_{1}$-antitrypsin deficiency patients with relatively high blood eosinophils. Respiration. 2018;95(2):114-121. doi:10.1159/000481867

24. Bafadhel M, Greening NJ, Harvey-Dunstan TC, et al. Blood eosinophils and outcomes in severe hospitalized exacerbations of COPD. Chest. 2016;150(2):320-328. doi:10.1016/j.chest.2016.01.026

25. Tsiligianni I, Kaplan AG. Are blood eosinophils a prime-time biomarker for COPD management decisions? Int J Chron Obstruct Pulmon Dis. 2018;13:1889-1891. doi:10.2147/COPD.S163749

26. Klion AD. Eosinophilia: a pragmatic approach to diagnosis and treatment. Hematology Am Soc Hematol Educ Program. 2015;2015 (1):92-97. doi:10.1182/asheducation-2015.1.92

27. Tsiligianni IG, Kosmas E, Van der Molen T, Tzanakis N. Managing comorbidity in COPD: a difficult task. Curr Drug Targets. 2013;14 (2):158-176. doi:10.2174/1389450111314020004

28. Nutman TB. Evaluation and differential diagnosis of marked, persistent eosinophilia. Immunol Allergy Clin North Am. 2007;27 (3):529-549. doi:10.1016/j.iac.2007.07.008

29. Fernandes FLA. Eosinophils in COPD: why should I care? J Bras Pneumol. 2016;42(4):237-238. doi:10.1590/s1806-37562016000400001

30. Liu H, Lazarus SC, Caughey GH, Fahy JV. Neutrophil elastase and elastase-rich cystic fibrosis sputum degranulate human eosinophils in vitro. Am J Physiol. 1999;276:28-34.

31. Costa CH, Rufino R, Silva JRL. Células inflamatórias e seus mediadores na patogênese da DPOC. Rev Assoc Med Bras. 2009;55 (3):347-354. doi:10.1590/S0104-42302009000300031

32. Hospers JJ, Schouten JP, Weiss ST, Rijcken B, Postma DS. Asthma attacks with eosinophilia predict mortality from chronic obstructive pulmonary disease in a general population sample. Am J Respir Crit Care Med. 1999;160(6):1869-1874. doi:10.1164/ajrccm.160.6.9811041

33. Singh D, Kolsum U, Brightling CE, Locantore N, Agusti A, TalSinger R; ECLIPSE investigators. Eosinophilic inflammation in COPD: prevalence and clinical characteristics. Eur Respir J. 2014;44(6):1697-1700. doi:10.1183/09031936.00162414 
34. Oshagbemi OA, Burden AM, Braeken DCW, et al. Stability of blood eosinophils in patients with chronic obstructive pulmonary disease and in control subjects, and the impact of sex, age, smoking, and baseline counts. Am J Respir Crit Care Med. 2017;195 (10):1402-1404. doi:10.1164/rccm.201701-0009LE
35. Shin SH, Park HY, Kang D, et al.; KOLD Study Group. Serial blood eosinophils and clinical outcome in patients with chronic obstructive pulmonary disease. Respir Res. 2018;19(1):134. doi:10.1186/s12931018-0840-X

\section{Publish your work in this journal}

The International Journal of COPD is an international, peer-reviewed journal of therapeutics and pharmacology focusing on concise rapid reporting of clinical studies and reviews in COPD. Special focus is given to the pathophysiological processes underlying the disease, intervention programs, patient focused education, and self management protocols. This journal is indexed on PubMed Central, MedLine and CAS. The manuscript management system is completely online and includes a very quick and fair peer-review system, which is all easy to use. Visit http://www.dovepress.com/testimonials.php to read real quotes from published authors.

Submit your manuscript here: https://www.dovepress.com/international-journal-of-chronic-obstructive-pulmonary-disease-journal 